\title{
The role of cost control in the financial management of small and medium-sized enterprises
}

\author{
Menglei $\operatorname{Sun}^{1 *}$ \\ ${ }^{1}$ Donghua University, Shanghai
}

\begin{abstract}
With the gradual acceleration of urbanization construction process, the economic level of China has b een significantly improved, especially the small and medium-sized enterprises under the support of national polici es have gradually accelerated the development speed in the process of urbanization construction, at the same time, to a certain extent, it has improved the economic interests and competitiveness, and promoted the subsequent rapi $\mathrm{d}$ development of small and medium-sized enterprises step by step. It is worth noting that in the process of acceler ating the development of small and medium-sized enterprises, the role and importance of financial management ar e increasingly highlighted. In order to ensure the full play of the role of financial management, people need to pay more attention to the application of financial management cost control. The main reason is that cost control is an $\mathrm{i}$ mportant part of financial management, which has an important impact on the development of enterprises and busi ness activities, and has a decisive role in the effectiveness of financial management of small and medium-sized ent erprises. Based on this, when small and medium-sized enterprises are facing increasing market competition, they must attach importance to the role of cost control in the financial management of enterprises, and try their best to $\mathrm{p}$ lay the actual effect of cost control, so as to provide continuous impetus for the development of small and medium -sized enterprises.
\end{abstract}

\section{INTRODUCTION}

Under the background of economic globalization, the frequency of trade between countries has gradually increased, and the development opportunities faced by China have gradually increased, and for small and medium-sized enterprises in China, they have begun to usher in a broader space for development. In the context of increasing development opportunities for SMEs, affected by the increasingly fierce international market competition, the actual development process of SMEs has gradually increased the pressure and challenges. The existence of this factor, to a certain extent, affects the subsequent development of small and medium-sized enterprises. Facing this situation, it is necessary for small and medium-sized enterprises to effectively respond to the increasing competition based on the application of scientific financial management methods. At the same time, we should pay more attention to cost control, ensure the effective cost reduction in all aspects of the enterprise by virtue of the role of cost control in financial management, promote the gradual increase of the actual interests of the enterprise, and provide protection for ourselves in the increasingly fierce market competition environment.

\section{COST CONTROL}

In short, cost control refers to the management and control work carried out by enterprises with planned cost; while cost control refers to the in-depth analysis, and the coordination, development and utilization of existing resources. This link is mainly based on management level and manual control, procurement of raw materials and processing of raw materials, and these factors have an important impact on cost control. On the basis of the above work, based on the relevant issues, and based on the application of effective measures, to ensure that the unnecessary consumption of enterprises can be effectively reduced, so as to ensure that the goal of minimum cost and maximum interest of enterprises can be well achieved. Enterprise cost management attaches great importance to cost reduction and cost demand satisfaction, and the purpose of cost management is to effectively prevent and avoid unnecessary waste of resources [1]. Based on the macro level analysis, in the process of carrying out cost management, the focus of all links is mainly on cost, which is embodied in material consumption and human control. The application of cost control in small and medium-sized enterprises can fully control all aspects of the enterprise, and at the same time excavate and effectively prevent the problems in the financial management of the enterprise to ensure the

\footnotetext{
*Corresponding author: sml20129@163.com
} 
gradual improvement of the level of financial management and the quality of cost control.

\section{THE ROLE OF COST CONTROL IN THE FINANCIAL MANAGEMENT OF SMALL AND MEDIUM-SIZED ENTERPRISES}

\subsection{Assist in financial analysis and comparison}

The application of cost control in the process of financial management of small and medium-sized enterprises, based on the active implementation of cost accounting, can provide great convenience for financial management personnel to conduct comprehensive analysis and comparison of accounts, and can also provide accurate basis for enterprise decision-making with the analysis results as a specific reference, thus providing guarantee for the correct formulation of various business and development decisions of enterprises [2]. In addition, the effective implementation of cost control in the financial management of small and medium-sized enterprises can promote the gradual improvement of the ability of small and medium-sized enterprises to repay debts, ensure the substantial improvement of the value of shareholders, and provide continuous impetus for the improvement of the economic efficiency and competitive strength of enterprises, ultimately providing sufficient guarantee for the good realization of the long-term development goals of enterprises

\subsection{Guarantee the optimal allocation of resources}

In the financial management of small and medium-sized enterprises, cost control enterprises, which play an important role, are also the full embodiment of the main tasks of financial management. The outstanding performance of cost control is to carry out cost control in the financial management of enterprises, based on the effectiveness of cost control, and then provide help for the effective optimization of the financial management and resource allocation of enterprises. In the process of carrying out specific cost control, effective measures should be taken to ensure that the role of cost control can be effectively exerted, so as to achieve the purpose of effective optimization of financial management and enterprise resource allocation [3]. It should be noted that when the cost control is applied in the financial management of an enterprise, the important prerequisite element is mainly cost, and the main method of cost accumulation is effective control.

\subsection{Promoting the balance of income and expenditure of enterprises}

Cost control in the financial management of small and medium-sized enterprises can effectively measure the cost indicators of enterprises, and provide a guarantee for the balance of income and expenditure of economic expenses such as the development of various businesses and activities of enterprises, thus promoting the good realization of the objectives of economic management and control of enterprises. On the basis of effectively carrying out cost control work and giving full play to the effectiveness of cost control, it can provide important help for enterprises to expand their own business scope and potential capacity mining, financial expenditure saving, etc. Therefore, the majority of small and medium-sized enterprises in today's society should put cost control in an important position in their own development process, and then based on the effective implementation of cost control in financial management, promote the continuous improvement and stable and sustainable development of economic benefits of enterprises from a positive perspective [4].

\section{COST CONTROL IN FINANCIAL MANAGEMENT OF SMALL AND MEDIUM ENTERPRISES}

\subsection{Unclear concept}

At present, the operation process of small and mediumsized enterprises is affected by a series of factors and problems. Even if the cost control work is actively carried out, it does not have strong work effectiveness. The main reason for this is that most of the small and medium-sized enterprises lack a clear concept of cost management [5]. Most of the small and medium-sized enterprises lack of relative advantages in scale when they carry out business development. Even so, many small and medium-sized enterprises have not paid more attention to cost control, and often subjectively believe that cost control is only a kind of financial management affairs. When the financial department carries out financial management, it usually gives priority to the opinions of the leaders. Affected by this factor, it is difficult for the financial department to effectively manage other departments. At the same time, it is difficult to pay attention to the independence of cost management and economic law, which ultimately makes the goal of maximizing the interests of most small and medium-sized enterprises difficult to achieve effectively, affecting the gradual improvement of the production efficiency of enterprises, but also poses threats and obstacles to the subsequent development of enterprises.

\subsection{The system is not perfect}

Cost management plays an important role in the financial management of most small and medium-sized enterprises in China. In order to effectively improve the level of financial management, we must take the actual operation of enterprises as the basis, and on this basis, actively establish a sound management system. However, from the current actual situation of most small and mediumsized enterprises, the effective establishment of enterprise cost control system has not been attached great importance, so the corresponding necessary cost control rules and regulations within most enterprises are extremely lacking. In the absence of specific systems, it 
is difficult to constrain the behavior of relevant employees in the work process, and ultimately unable to ensure the effective improvement of work efficiency and work quality [6]. It is worth noting that when employees do not have a high sense of responsibility, it is easy to lead to adverse phenomenon such as employee profit making, and gradually lose corporate assets. At the same time, it is also extremely adverse to the formation of a good atmosphere within the enterprise, which hinders the stable and sustainable development of the enterprise in the future.

\subsection{No emphasis on comprehensiveness}

Through the effective implementation of pre control work, the cost of each link of the enterprise can be controlled, so as to promote the gradual improvement of enterprise interests; during the process of cost control in the process, the capital expenditure of staff work and raw material procurement can be controlled, so as to provide protection for reducing unnecessary costs of multiple links of the enterprise; The purpose of the post control work of the enterprise is to control the sales process after the completion of the production of the products. Under the effective control of this process, it can provide further protection for the effective avoidance and prevention of waste in each process, so as to provide effective maintenance for the economic interests of the enterprise [7]. However, from the current actual situation of most small and medium-sized enterprises, they have not paid more attention to the comprehensive cost control. At the same time, the company did not actively carry out cost control work in advance, in the process and after the event based on the relevant regulations, so it will inevitably increase the company's expenditure in the intangible, waste a lot of resources, and at the same time, it will be extremely adverse to the overall efficiency of the company.

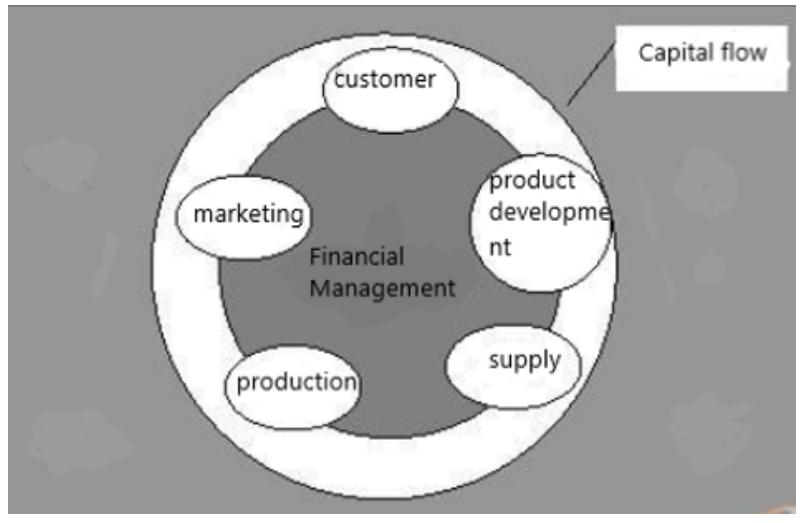

Figure 1. Diagram of cost control in financial management objectives

\section{COST CONTROL MEASURES IN FINANCIAL MANAGEMENT OF SMALL AND MEDIUM-SIZED ENTERPRISES}

\subsection{Strengthen strategic awareness}

Small and medium-sized enterprises and relevant management personnel should actively improve their backward ideas. At the same time, the awareness of cost control strategy has been continuously strengthened. Based on the effective establishment of the concept of financial cost, the cost savings in the process of carrying out work in each link and the strategic awareness of longterm development of enterprises have been effectively formed, thus laying a solid spiritual foundation for the stable and sustainable development of small and medium-sized enterprises. For small and medium-sized enterprises in the fierce competition environment, we should focus on the analysis of the actual operation of enterprises on the basis of certain income. At the same time, the company actively carried out cost control control to restrain and control various expenses of the enterprise, and promoted the gradual increase of enterprise profits on the basis of which, so as to not only ensure the gradual improvement of economic benefits of the enterprise, but also promote the subsequent development of the enterprise with a new source of power, providing a positive role for the healthy and stable operation and development of the enterprise [8].

\subsection{Improve relevant systems}

When carrying out the cost control work in the financial management of small and medium-sized enterprises, we should actively establish a sound cost control system based on our own actual situation, and optimize and innovate the financial management with the help of modern financial control methods. When establishing a specific system, the actual development of the enterprise should be integrated to ensure that the established system is more reasonable, effective and feasible, and on this basis, the employees of the enterprise should be effectively constrained. At the same time, when enterprises carry out cost control work, they should actively break through the traditional methods and make full use of accounting computerization to ensure that financial personnel are fully liberated in the heavy accounting and accounting work [9]. It is worth noting that enterprises should also strengthen the training of professional skills of financial personnel. Based on the regular or irregular internal training, it can help the financial personnel to gradually improve their skills, ensure the continuous strengthening of their sense of responsibility, and make the foundation for the continuous improvement of the financial management level of enterprises more solid. 


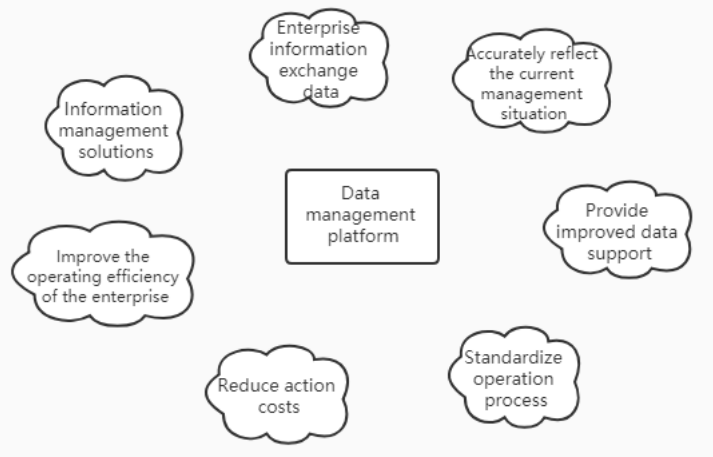

Figure 2. Accounting of ERP enterprise financial management module

\subsection{Emphasis on comprehensive control}

In order to effectively improve the financial management level of the enterprise, the company should pay more attention to the cost control, and at the same time, the company should also focus on all aspects of cost control, and strengthen cost control in advance, in the process and after the event. When carrying out the pre control work, we should take the actual operation of the enterprise as the basis, and then predict the results based on the application of reasonable prediction method, and formulate the specific plan on this basis, so as to control the expenditure and ensure the orderly development of the subsequent work. During the process of control, we should strictly control the procurement of raw materials and human cost of the enterprise, effectively check the data of each link, provide guarantee for the maximum use of enterprise resources, and then effectively reduce the operating costs of the enterprise. The post control link needs to manage data. When an enterprise sells its products, it should actively assess the cost control efficiency, and at the same time actively formulate the financial cost control documents for specific events, so as to provide guarantee for the effective implementation of cost management in each link of the enterprise.

\subsection{Risk monitoring and early warning}

In order to ensure that small and medium-sized enterprises can better prevent and avoid financial risks, it is necessary to dynamically and timely monitor and early warn the financial risks of enterprises. The senior management of an enterprise shall quickly and accurately determine the financial plan that is in line with the enterprise's own development, go deep into the market and grassroots level, and combine with the actual situation of the enterprise to ensure that their keen market insight and risk response ability are continuously improved, and help enterprises to effectively avoid potential financial risks in investment, financing, merger and acquisition and other large-scale capital activities. At the same time, with the help of the active establishment of the early warning mechanism of financial risks of enterprises, it can help enterprises to minimize financial risks and promote the continuous improvement of economic benefits of enterprises [10]. The important content in the cost control of an enterprise is risk detection and early warning. Only when an enterprise has sufficient foresight and foresight of risks, can it provide a comprehensive guarantee for the stable survival and healthy development of an enterprise in the fierce competition environment, and the maximization of economic benefits.

\section{ConClusion}

This paper first analyzes the role of cost control in the financial management of small and medium-sized enterprises, and on this basis explores the specific application of cost control in financial management, hoping to provide reference for the gradual improvement of the financial management effectiveness of small and medium-sized enterprises in the fierce competition environment in the current society. At the same time, it is suggested that the majority of small and medium-sized enterprises in the current society should attach great importance to the role of cost control when carrying out financial management, and take effective measures to play the role of cost control based on the mining of practical problems, so as to provide favorable conditions for the continuous improvement of the level of financial management, economic benefits and competitive strength of enterprises.

\section{REFERENCES}

1. Huang Haihui. Analysis on the problems and Countermeasures of cost management of small and medium-sized enterprises $[\mathrm{J}]$. finance and accounting learning, 2020 (25): 140-141+144.

2. Li Fangzhou. Research on the effect of cost control on the achievement of financial management objectives of enterprises $[\mathrm{J}]$. industrial technology innovation, 2020,2 (13): 85-86.

3. Zhang Jianing. Analysis of the importance of cost control in the financial management of small and medium-sized enterprises [J]. Shang Xun, 2020 (13): $58+60$.

4. Yang Xin. Analysis on the role of cost control in achieving the financial management objectives of enterprises [J]. modern economic information, 2019 (20): $168+170$.

5. Dong le. The importance of cost control in the financial management of small and medium-sized enterprises [J]. times economic and trade, 2019 (30): 30-31.

6. Zheng Lin. Research on the effect of cost control on the realization of financial management objectives of enterprises $[\mathrm{J}]$. finance and accounting learning, 2019 (08): 85-86.

7. Sun Jiayu. The role and application of cost control in enterprise financial management $[\mathrm{J}]$. science and technology information, 2018,16 (21): 149-150.

8. Feng Fenlian. Positive effect of cost control on the achievement of financial management objectives $[\mathrm{J}]$. 
enterprise reform and management, 2018 (07): $159+162$.

9. Han Yingchao. The role and application of cost control in enterprise financial management [J]. China collective economy, 2018 (07): 132-133.

10. Hu Xiaoyuan. The importance of cost control in the financial management of small and medium-sized enterprises $[\mathrm{J}]$. international business accounting, 2018 (02): 89-91. 